\title{
Case Report \\ Clinically Undiagnosed Prostate Carcinoma Metastatic to Renal Oncocytoma
}

\author{
Adam J. Horn, ${ }^{1}$ Bari E. Fritz, ${ }^{1}$ Chad A. LaGrange, ${ }^{2}$ William W. West, ${ }^{1}$ and Subodh M. Lele ${ }^{1}$ \\ ${ }^{1}$ Department of Pathology and Microbiology, University of Nebraska Medical Center, Omaha, NE 68198, USA \\ ${ }^{2}$ Division of Urology, Department of Surgery, University of Nebraska Medical Center, Omaha, NE 68198, USA
}

Correspondence should be addressed to Adam J. Horn, ahor1@unmc.edu

Received 5 March 2012; Accepted 11 April 2012

Academic Editors: S. J. Hong and M. Sheikh

Copyright ( 2012 Adam J. Horn et al. This is an open access article distributed under the Creative Commons Attribution License, which permits unrestricted use, distribution, and reproduction in any medium, provided the original work is properly cited.

\begin{abstract}
Tumors-to-tumor metastasis is an uncommon occurrence and can be a source of great diagnostic difficulty, especially when the donor tumor is undiagnosed. Here we report a case of a kidney resected for a primary neoplasm (oncocytoma) that harbored metastases from a clinically undiagnosed prostatic adenocarcinoma. The presence of the poorly differentiated metastasis within an otherwise typical oncocytoma in the absence of metastases in the surrounding nonneoplastic renal parenchyma resulted in a diagnostic dilemma. To our knowledge, this is the first report of a case in the English literature of a clinically undiagnosed prostatic adenocarcinoma metastatic to a renal oncocytoma identified on examination of the resected renal neoplasm.
\end{abstract}

\section{Introduction}

While tumor metastasis is a common occurrence, the tumorto-tumor metastasis is quite rare, being first documented in 1902. The most common donor site is lung, followed by breast, prostate, and thyroid carcinomas [1]. The kidney (in particular, renal cell carcinoma) is the most common recipient, followed by sarcomas, meningiomas, thyroid, and pituitary adenomas $[1,2]$. In addition to renal cell carcinoma, angiomyolipomas and renal oncocytomas have been described as being recipients $[3,4]$. In this paper we present a case of renal oncocytoma harboring metastases from a previously undiagnosed prostatic adenocarcinoma. To the best of our knowledge, there has been no documented cases of prostatic adenocarcinoma with metastasis to a renal oncocytoma.

\section{Case Report}

A 92-year-old man presented with complaints of low back pain. He had magnetic resonance imaging of the spine performed which incidentally revealed a mass in the left kidney. A CT scan confirmed this finding, demonstrating a $6 \mathrm{~cm}$ solid enhancing mass in the left kidney, in addition to multiple bilateral lung nodules and lesions in the spine worrisome for metastatic disease. He was presumed to have metastatic renal cell carcinoma and underwent a radical nephrectomy.

Dissection of the radical nephrectomy specimen revealed a solitary tumor measuring $7.4 \times 5.8 \times 3.5 \mathrm{~cm}$, which was well circumscribed, tan-brown, and confined to the kidney. Microscopic examination of the renal tumor revealed areas typical of an oncocytoma with an archipelaginous architectural pattern near the center of the tumor (Figure 1). In addition to the oncocytic cells, a second population of cells arranged in small groups containing high nuclear/cytoplasmic ratios, nuclear hyperchromasia, occasional prominent nucleoli, and rare mitoses were noted (Figure 2). The nests were restricted to the oncocytic neoplasm and were not present in several additional sections from the surrounding grossly unremarkable renal parenchyma. The second population of cells was strongly positive for PSA, PAP, cytokeratin (AE1/AE3), and EMA, confirming the diagnosis of prostatic adenocarcinoma metastatic to renal oncocytoma. The pathologic diagnosis led to testing for serum PSA ( $>500 \mathrm{ng} / \mathrm{mL}$ ), and the subsequent prostate needle biopsy demonstrated a high-grade prostatic adenocarcinoma with a Gleason score of $9(4+5)$ that was 


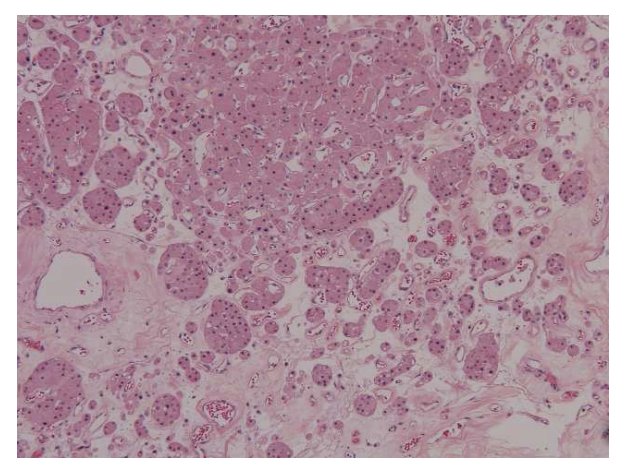

Figure 1: Oncocytoma. Note the archipelaginous architectural pattern with oncocytic cells (hematoxylin and eosin; original magnification $\times 40$ ).

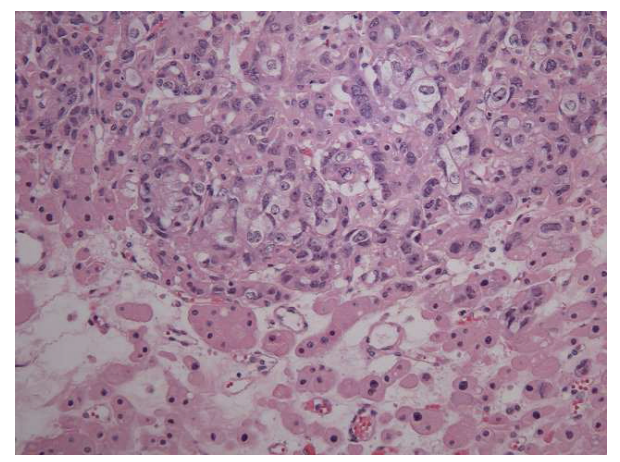

Figure 2: A second population of cells with malignant cytologic features is noted admixed within the oncocytoma (hematoxylin and eosin; original magnification $\times 200$ ).

morphologically similar to the metastatic deposits within the renal oncocytoma.

\section{Discussion}

Although the incidence of more than one neoplastic processe occurring simultaneously in a patient ranges from 4.2 to $8 \%$, the documented metastasis of one neoplasm to another is extremely rare, with less than 100 cases being reported in the English literature $[3,5,6]$. It is theorized that neoplasms produce substances that restrict the growth of other cells $[1,7]$. It has also been suggested that the rapid growth of neoplasms creates a nutritionally competitive environment $[8,9]$. Campbell et al. described criteria for the diagnosis of a tumor-to-tumor metastasis: (1) more than 1 primary tumor must exist, (2) the recipient tumor is a true benign or malignant neoplasm, (3) the metastatic neoplasm is a true metastasis with established growth in the host tumor, not the result of contiguous growth (a so-called "collision tumor") or tumor embolization, and (4) neoplasms that have metastasized to the lymphatic system where lymphoreticular tumors already exist are excluded. This case fits all criteria.

Prostatic adenocarcinoma has high propensity for metastasis to bone and much metastasizes to visceral organs with far less frequency. One explanation for the strong attraction
TABLE 1: Known cases of tumor-to-tumor metastasis with renal oncocytoma as recipient.

\begin{tabular}{lccc}
\hline & Age & Sex & Donor Site \\
\hline Olsen et al. [17] & 71 & Male & Small cell, lung \\
Ben-Izhak et al. [16] & 63 & Male & Small cell, lung \\
Altinok et al. [3] & 64 & Male & Squamous cell carcinoma, lung \\
Present case & 92 & Male & Prostatic adenocarcinoma \\
\hline
\end{tabular}

to bone is that prostate tumor cells will bind to human bone marrow endothelial cells with a higher affinity than other endothelial cells [10]. In cases of tumor-to-tumor metastasis, prostate cancer is a rare donor tumor, with 4 previously reported cases metastasizing to renal cell carcinoma, 1 to a follicular adenoma of the thyroid, and 1 to a pituitary adenoma $[8,11-15]$.

The kidney is a common recipient for tumor-to-tumor metastasis, which is thought to be partially due to the rich vascular supply of the kidney $[1,6]$. Renal cell carcinoma is the most common recipient, with over 60 cases being reported [1]. However, there has only been 3 previously described cases of metastatic disease to renal oncocytoma (Table 1) $[3,16,17]$. This case represents the first reported case of prostatic adenocarcinoma to renal oncocytoma. This case is also of interest because the prostate cancer was undiagnosed at the time of its discovery within the oncocytoma.

In conclusion, this case emphasizes the need to entertain tumor-to-tumor metastasis when encountering a diagnostically difficult or unusual case. The judicious use of immunoperoxidase staining panels can be of assistance in reaching a final, accurate diagnosis.

\section{References}

[1] C. Petraki, M. Vaslamatzis, T. Argyrakos et al., "Tumor to tumor metastasis: report of two cases and review of the literature," International Journal of Surgical Pathology, vol. 11, no. 2, pp. 127-135, 2003.

[2] L. V. Campbell Jr., E. Gilbert, C. R. Chamberlain Jr., and A. L. Watne, "Metastases of cancer to cancer," Cancer, vol. 22, no. 3, pp. 635-643, 1968.

[3] G. Altinok, G. Guler, and A. Sahin, "Tumor metastasis to an oncocytoma," Scandinavian Journal of Urology and Nephrology, vol. 33, pp. 16-17, 1999.

[4] R. Ricketts, P. Tamboli, B. Czerniak, and C. C. Guo, "Tumorto-tumor metastasis: report of 2 cases of metastatic carcinoma to angiomyolipoma of the kidney," Archives of Pathology and Laboratory Medicine, vol. 132, no. 6, pp. 1016-1020, 2008.

[5] L. A. Granville, M. L. Ostrowski, L. D. Truong, and S. Shen, "Pathologic quiz case: unusual morphology in an otherwise classic renal cell carcinoma. Tumor-to-tumor metastasis: pulmonary adenocarcinoma metastatic to clear cell renal cell carcinoma," Archives of Pathology and Laboratory Medicine, vol. 129, no. 2, pp. e49-e50, 2005.

[6] T. Sawada, H. Takahashi, K. Hasatani et al., "Tumor-to-tumor metastasis: report of an autopsy case of lung adenocarcinoma metastasizing to renal cell carcinoma," Internal Medicine, vol. 48 , no. 17 , pp. 1525-1529, 2009. 
[7] S. M. Rabson, P. L. Stier, J. C. Baumgartner, and D. Rosenbaum, "Metastasis of cancer to cancer," American Journal of Clinical Pathology, vol. 24, no. 5, pp. 572-579, 1954.

[8] I. Gore and R. Barr, "Metastasis of cancer to cancer," AMA Archives of Pathology, vol. 66, no. 3, pp. 293-298, 1958.

[9] J. D. Maloney and M. Immergut, "The kidney as host in cancer-to-cancer metastasis," Journal of Urology, vol. 98, no. 6, pp. 657-660, 1967.

[10] J. K. Jin, F. Dayyani, and G. E. Gallick, "Steps in prostate cancer progression that lead to bone metastasis," International Journal of Cancer, vol. 128, no. 11, pp. 2545-2561, 2011.

[11] H. Inatomi, Y. Yamada, and T. Okamura, "A case of prostate carcinoma metastasizing to renal cell carcinoma," International Journal of Urology, vol. 3, no. 2, pp. 155-157, 1996.

[12] B. Majmudar, "Metastasis of cancer to cancer: report of a case," Human Pathology, vol. 7, no. 1, pp. 117-119, 1976.

[13] J. A. Ramsay, K. Kovacs, B. W. Scheithauer, C. Ezrin, and M. H. Weiss, "Metastatic carcinoma to pituitary adenomas: a report of two cases," Experimental and Clinical Endocrinology, vol. 92, no. 1, pp. 69-76, 1988.

[14] J. Y. Ro, C. Guerrieri, A. K. H. Naggar, N. G. Ordonez, J. G. Sorge, and A. G. Ayala, "Carcinomas metastatic to follicular adenomas of the thyroid gland: report of two cases," Archives of Pathology and Laboratory Medicine, vol. 118, no. 5, pp. 551556, 1994.

[15] L. Tiszlavicz, T. Krenacs, and Z. Rozsa, "Prostatic cancer metastasized into the kidney and kidney cancer metastasized into the lung," Orvosi Hetilap, vol. 132, no. 28, pp. 1539-1542, 1991.

[16] O. Ben-Izhak and C. Lichtig, "Renal oncocytoma harbouring metastatic lung carcinoma. A case report," Scandinavian Journal of Urology and Nephrology, vol. 24, no. 4, pp. 317-318, 1990.

[17] J. H. Olsen, O. S. Nielsen, and U. Engel, "Neoplasm to neoplasm metastasis. A renal oncocytoma with metastatic bronchogenic carcinoma," Scandinavian Journal of Urology and Nephrology, vol. 18, no. 3, pp. 255-256, 1984. 


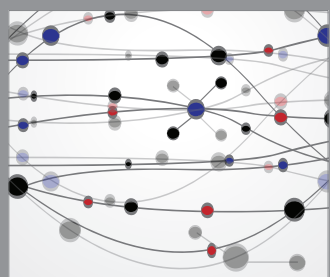

The Scientific World Journal
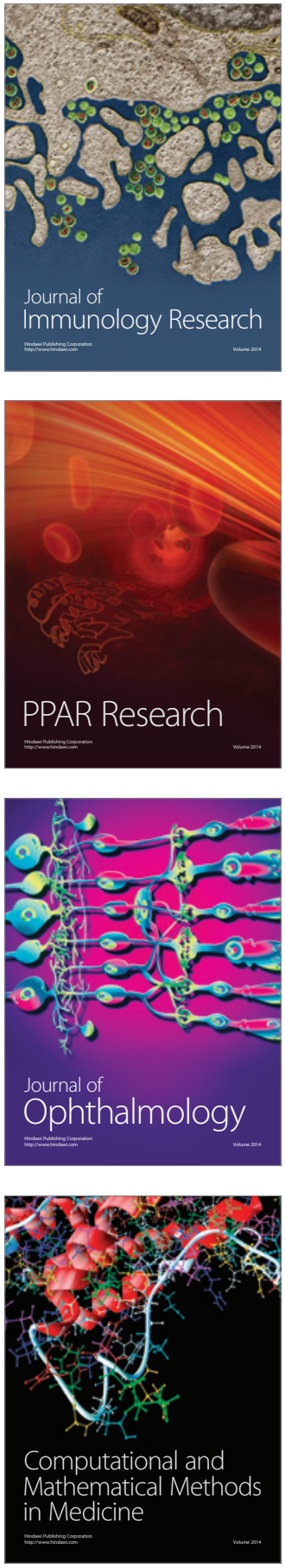

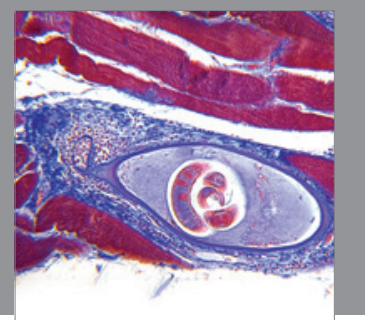

Gastroenterology

Research and Practice
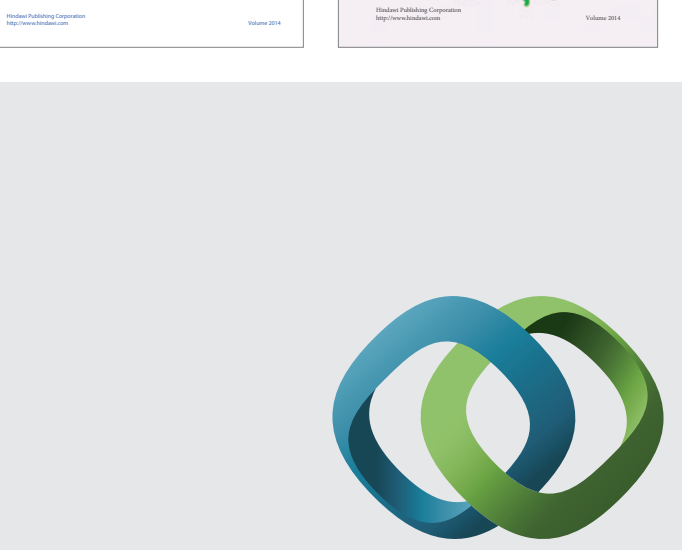

\section{Hindawi}

Submit your manuscripts at

http://www.hindawi.com
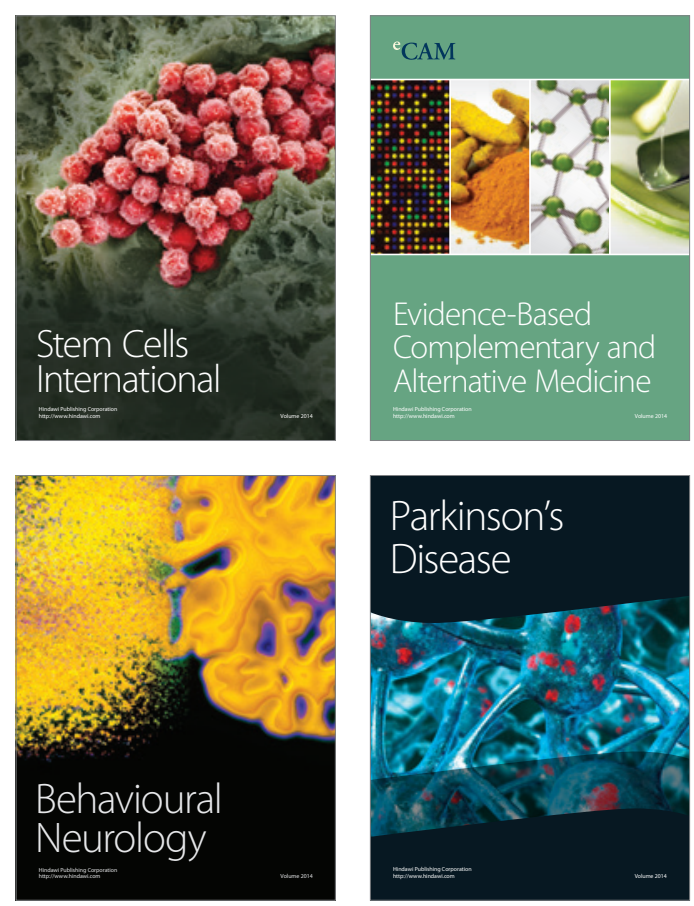

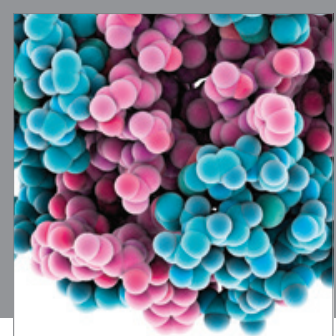

Journal of
Diabetes Research

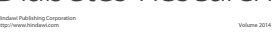

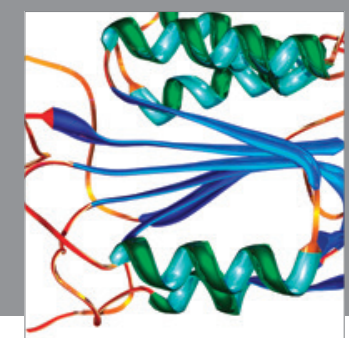

Disease Markers
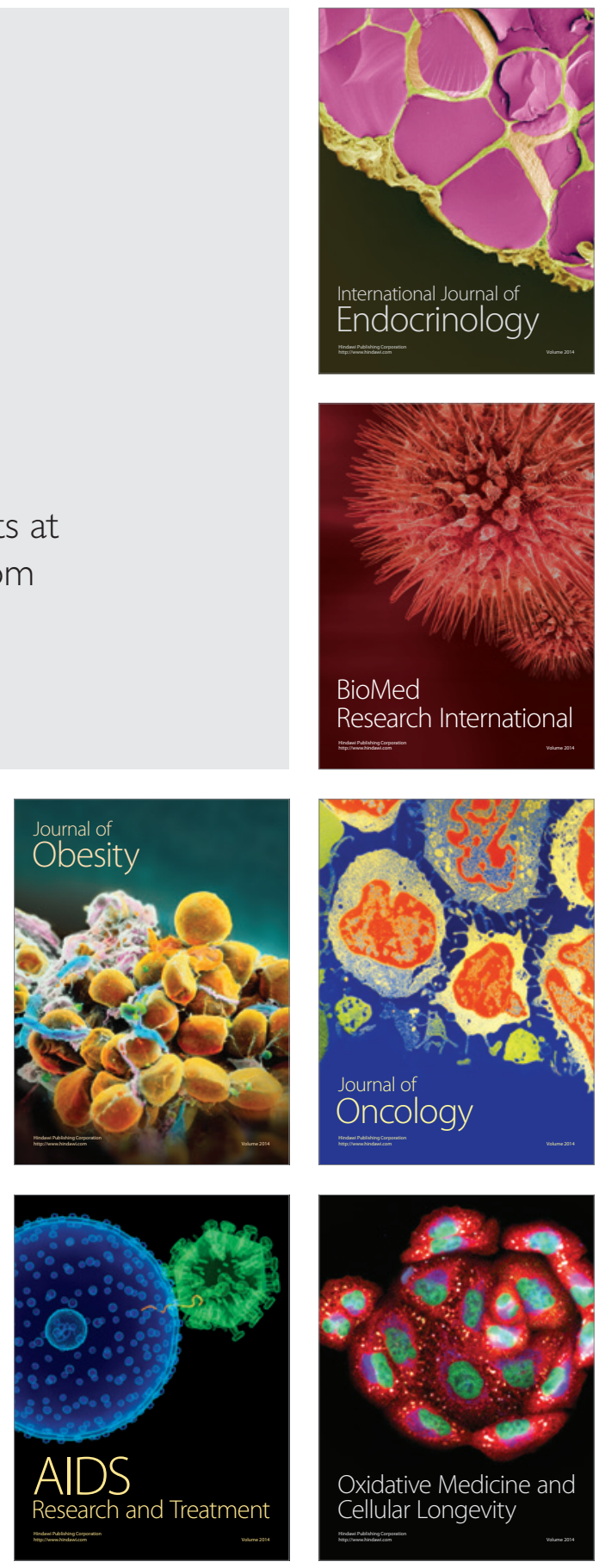